\title{
In Vitro Assessment of Re-treatment Options for Patients with Hepatitis C Virus Genotype 1b Infection Resistant to Daclatasvir Plus Asunaprevir
}

Jacques Friborg $\cdot$ Nannan Zhou $\cdot$ Zhou Han $\cdot$

Xiaoyan Yang $\cdot$ Paul Falk $\cdot$ Patricia Mendez .

Fiona McPhee

To view enhanced content go to www.infectiousdiseases-open.com

Received: October 30, 2014 / Published online: December 17, 2014

(C) The Author(s) 2014. This article is published with open access at Springerlink.com

\section{ABSTRACT}

Introduction: Daclatasvir is a non-structural protein 5A (NS5A) inhibitor with activity against hepatitis $\mathrm{C}$ virus (HCV) genotypes 1-6 in vitro, and asunaprevir is a non-structural protein 3 (NS3) protease inhibitor with activity against genotypes $1,4,5$, and 6 . This study evaluates potential options for the re-treatment of HCV genotype $1 \mathrm{~b}$-infected patients who have failed combination therapy with daclatasvir plus asunaprevir.

Methods: The antiviral activity of drug combination regimens in $\mathrm{HCV}$ subgenomic

Electronic supplementary material The online version of this article (doi:10.1007/s40121-014-0052-8) contains supplementary material, which is available to authorized users.

J. Friborg $\cdot$ N. Zhou $\cdot$ Z. Han $\cdot$ X. Yang $\cdot$ P. Falk · F. McPhee $(\bowtie)$

Bristol-Myers Squibb Research and Development, 5 Research Parkway, Wallingford, CT 06492, USA

e-mail: fiona.mcphee@bms.com

P. Mendez

Bristol Myers-Squibb Research and Development, Lawrenceville, NJ, USA replicon cell lines representing genotype $1 \mathrm{~b}$ (Con1 strain) wild-type or a variant with specific NS5A and NS3 amino acid substitutions conferring resistance to daclatasvir and asunaprevir were compared using replicon elimination assays. Drug concentrations representing multiple 50\% effective concentrations $\left(\mathrm{EC}_{50}\right)$ derived in vitro and trough plasma concentrations observed in a clinical setting were utilized.

Results: At multiple $\mathrm{EC}_{50}$ values of each drug $\left(3 \times, 10 \times\right.$, and $\left.30 \times \mathrm{EC}_{50}\right)$, combinations of daclatasvir plus sofosbuvir, sofosbuvir plus ledipasvir, sofosbuvir plus simeprevir, and sofosbuvir plus either a next-generation NS3 or NS5A inhibitor demonstrated comparable activity in wild-type and daclatasvir/ asunaprevir-resistant cell lines. At clinically relevant drug trough concentrations, combination regimens of daclatasvir plus asunaprevir plus beclabuvir ( \pm ribavirin), and daclatasvir plus asunaprevir plus beclabuvir plus sofosbuvir efficiently cleared daclatasvir + asunaprevir-resistant replicons from cells within 5 days of treatment. 
Conclusion: Our in vitro results highlight a number of potential all-oral treatment options for patients who do not achieve a sustained virologic response following therapy with daclatasvir plus asunaprevir. These results require further evaluation in clinical studies.

Keywords: Asunaprevir; Beclabuvir;

Daclatasvir; Hepatitis C virus; Ledipasvir;

Replicon; Resistance; Re-Treatment; Simeprevir; Sofosbuvir

\section{INTRODUCTION}

Current options for the treatment of hepatitis $\mathrm{C}$ virus (HCV) infection are evolving rapidly with the recent approval of several directacting antiviral (DAA) agents. Daclatasvir (DCV) is a non-structural protein 5A (NS5A) inhibitor with activity against HCV genotypes 1-6 in vitro [1]. Asunaprevir (ASV) is a nonstructural protein 3 (NS3) protease inhibitor with activity against genotypes 1, 4, 5, and 6 [2]. The all-oral, interferon-free combination of DCV + ASV provided high rates of sustained virologic response and was well tolerated in genotype 1b-infected patients in global and Japanese Phase III studies [3, 4]. Among genotype 1b-infected patients who experience virologic escape with DCV + ASV, the most common resistance-associated variants (RAVs) detected together after $\mathrm{HCV}$ RNA rebound occur at NS5A positions L31 and Y93, and NS3 position D168. Here, we aim to evaluate potential re-treatment options for genotype 1b-infected patients who have previously failed combination therapy with DCV + ASV using the in vitro HCV replicon system.

\section{METHODS}

HCV subgenomic replicon cell lines representing genotype $1 \mathrm{~b}$ (Con 1 strain) wildtype or a variant with specific NS5A and NS3 amino acid substitutions conferring resistance to DCV and ASV (NS5A-L31M-Y93H and NS3-D168V, respectively) were established as previously described [5]. Peginterferon alfa-2a (PEGASYS $^{\circledR}$ ) was purchased from Hoffman-La Roche, Inc. (Nutley, NJ, USA) and ribavirin (RBV) was purchased from Sigma-Aldrich Co. (St. Louis, MO, USA). Simeprevir (SMV; NS3 inhibitor), sofosbuvir (SOF; NS5B inhibitor), and ledipasvir (LDV; NS5A inhibitor) were synthesized at Bristol-Myers Squibb, and have been described previously [6-8]. DCV, ASV, beclabuvir (BCV; BMS-791325; NS5B thumb 1 inhibitor), BMS-1 (next-generation NS5A inhibitor), and BMS-2 (next-generation NS3 inhibitor) were also synthesized at BristolMyers Squibb. The antiviral activities of the individual compounds and combination regimens were assessed using phenotypic analyses (to determine 50\% effective concentrations $\left[\mathrm{EC}_{50}\right]$ ) and replicon elimination assays, as described previously $[9,10]$. The ability of drug combinations to clear replicons was evaluated using two different approaches. First, wild-type and DCV + ASV-resistant replicon cell lines with a neo-selectable marker were incubated without G418 for 1, 3, 7, 11 or 14 days with multiples of $\mathrm{EC}_{50}$ values for each drug $(3 \times, 10 \times$, and $30 \times \mathrm{EC}_{50}$ ) determined against wild-type replicon. Combination regimens of $\mathrm{DCV}+\mathrm{ASV}, \quad \mathrm{DCV}+\mathrm{SOF}, \quad \mathrm{SOF}+\mathrm{LDV}$, $\mathrm{SOF}+\mathrm{SMV}, \quad \mathrm{DCV}+\mathrm{ASV}+\mathrm{BCV}$ and $\mathrm{DCV}+$ $\mathrm{ASV}+\mathrm{BCV}+\mathrm{SOF}$ were assessed initially using multiple $\mathrm{EC}_{50}$ values of each agent estimated against wild-type replicon. RBV was examined at $1 \times \mathrm{EC}_{50}$ concentration, tenfold below any 
Table 1 Cell potency of compounds against genotype $1 \mathrm{~b}$ wild-type (Con1) and DCV + ASV-resistant replicons and $\mathrm{C}_{\text {trough }}$ concentration observed in clinical settings

\begin{tabular}{lcccc}
\hline Agent & $\mathbf{E C}_{\mathbf{5 0}}(\mathbf{\pm S D}), \mathbf{n M}^{*}$ & & $\mathbf{C}_{\text {trough }} \mathbf{n M}^{*}$ \\
\cline { 2 - 4 } & GT 1b (Con1) replicon & $\begin{array}{c}\text { GT 1b NS3-D168V, } \\
\text { NS5A-L31M-Y93H }\end{array}$ & Fold change & \\
\hline Asunaprevir & $2.0 \pm 0.4$ & $401 \pm 102$ & 201 & $40^{\dagger}$ \\
Daclatasvir & $0.002 \pm 0.001$ & $49 \pm 9$ & 24,500 & $250^{\dagger}$ \\
Beclabuvir & $3.4 \pm 0.2$ & $4.0 \pm 0.7$ & 1 & $500^{\dagger}$ \\
Ledipasvir & $0.002 \pm 0.0004$ & $131 \pm 40$ & 65,500 & $120[20]$ \\
Sofosbuvir & $147 \pm 27$ & $102 \pm 12$ & 1 & $1,100^{\dagger}$ \\
Simeprevir & $1.9 \pm 0.1$ & $6,296 \pm 203$ & 3,313 & $2,200^{\dagger}$ \\
Next-gen NS5A (BMS-1) & $0.010 \pm 0.002$ & $0.354 \pm 0.05$ & 39 & - \\
Next-gen NS3 PI (BMS-2) & $0.7 \pm 0.1$ & $4.1 \pm 0.6$ & 6 & $100^{\ddagger}$ \\
Ribavirin* & $8.1 \pm 1.2$ & $7.8 \pm 5.7$ & 1 & $2.5[21]$ \\
Peginterferon alfa & $1.2 \pm 0.2$ & $2.6 \pm 0.6$ & 2 & $15[22]$ \\
\hline
\end{tabular}

$C_{\text {trough }}$ trough plasma concentrations, $E C_{50} 50 \%$ effective concentrations, GT genotype, NS3 non-structural protein 3, $N S 5 A$ non-structural protein $5 \mathrm{~A}, P I$ protease inhibitor, $S D$ standard deviation

${ }^{*}$ All $\mathrm{EC}_{50}$ and $\mathrm{C}_{\text {trough }}$ concentrations are $\mathrm{nM}$, except for ribavirin $(\mu \mathrm{g} / \mathrm{mL})$ and peginterferon alfa $(\mathrm{ng} / \mathrm{mL})$

$\dagger$ BMS data on file

* Estimated value

observed cell toxicity. In another approach, replicon cell lines were incubated without G418 for 1, 2, 3, 5 and 7 days with drug concentrations representing trough plasma concentrations $\left(\mathrm{C}_{\text {trough }}\right)$ observed in a clinical setting. In both approaches, the drug regimen was removed at the end of the incubation period and the cell cultures were further maintained for 2 weeks in growth medium supplemented with G418 $(0.5 \mathrm{mg} / \mathrm{mL})$ to monitor replicon elimination. Surviving replicon colonies were fixed and stained with crystal violet as described previously [10].

\section{RESULTS}

Phenotypic analyses indicated that DCV + ASVresistant replicon cell lines conferred high levels of resistance to DCV, LDV, ASV and SMV, relative to the wild-type reference replicon (Table 1). In contrast, $\mathrm{EC}_{50}$ values for $\mathrm{BCV}$, peginterferon alfa, RBV and SOF were similar in both cell lines. The next-generation NS5A (BMS-1) and NS3 (BMS-2) protease inhibitors demonstrated improved potency (39-fold and 6-fold reduction in anti-HCV activity, respectively, relative to wild type) in the $\mathrm{DCV}+\mathrm{ASV}$-resistant replicon when compared to the activities of DCV and ASV (24,500-fold and 201-fold reduction in anti-HCV activity, respectively). HCV replicon elimination results for days 3, 7 and 14 are shown in Fig. 1 (complete results for Days 1, 3, 7, 11 and 14 are provided in Supplementary Fig. 1). With 14 days of treatment, two-DAA regimens of $\mathrm{DCV}+\mathrm{ASV}, \quad \mathrm{DCV}+\mathrm{SOF}, \quad \mathrm{SOF}+\mathrm{LDV}$ and SOF + SMV demonstrated comparable activity 


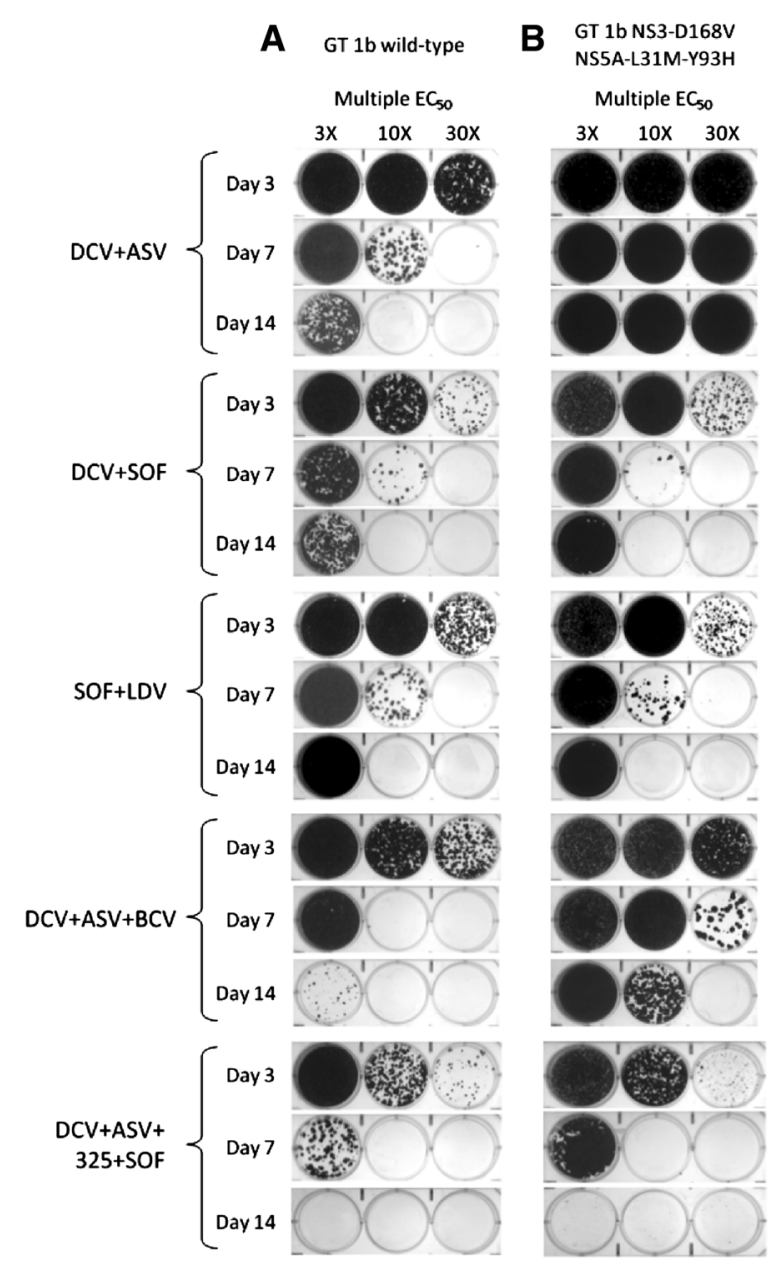

Fig. $1 \mathrm{HCV}$ replicon elimination assays using a wild-type GT1b and b DCV + ASV-resistant (NS3-D168V, NS5A-L31M-Y93H) replicon cell lines treated with indicated combination regimens at multiple $\mathrm{EC}_{50}$ values for each agent (determined in wild-type replicon). Data for Days 3, 7, and 14 are shown; complete data are shown in Supplementary Fig. 1. $A S V$ asunaprevir, $B C V$ beclabuvir, $D C V$ daclatasvir, $G T$ genotype, $H C V$ hepatitis $\mathrm{C}$ virus, $L D V$ ledipasvir, $N S 3$ non-structural protein 3, NSSA nonstructural protein $5 \mathrm{~A}, S M V$ simeprevir, $S O F$ sofosbuvir

in eliminating wild-type replicons at $10 \times \mathrm{EC}_{50}$ values (Fig. 1a). The three-DAA regimen of $\mathrm{DCV}+\mathrm{ASV}+\mathrm{BCV}$ and the four-DAA regimen of $\mathrm{DCV}+\mathrm{ASV}+\mathrm{BCV}+\mathrm{SOF}$ demonstrated increased efficacy with complete clearance of wild-type replicons observed with the four-DAA regimen by day 11 at $3 \times \mathrm{EC}_{50}$ values. Similar results were observed with SOF in combination with either the next-generation NS3 protease inhibitor or a next-generation NS5A inhibitor (Supplementary Fig. 1). As expected, $\mathrm{DCV}+\mathrm{ASV}$ did not eliminate replicons harboring NS5A-L31M-Y93H and NS3-D168V, which confer reduced susceptibilities to both compounds (Fig. 1b). The elimination of replicons by $\mathrm{DCV}+\mathrm{SOF}, \quad \mathrm{SOF}+\mathrm{LDV}$, $\mathrm{SOF}+\mathrm{SMV}$, and SOF + next-generation NS3 protease or NS5A inhibitor was comparable in wild-type and DCV + ASV-resistant cell lines. The combination of DCV + ASV + BCV showed reduced activity against $\mathrm{DCV}+\mathrm{ASV}$-resistant replicons compared with wild type. To further evaluate the use of these combination regimens, replicon elimination assays were performed at drug concentrations based on clinically relevant $\mathrm{C}_{\text {trough }}$ concentrations (Table 1). Monotherapy at $\mathrm{C}_{\text {trough }}$ concentrations demonstrated the high potency of the NS5A inhibitors, DCV and LDV, compared with the other agents tested (Fig. 2a). With $\mathrm{EC}_{50}$ values in the picomolar range that are well below the high plasma $\mathrm{C}_{\text {trough }}$ concentrations obtained in clinical settings, treatment with these DAAs was sufficient in eliminating wild-type replicons within 7 days. Conversely, none of the NS5A inhibitors and NS3 protease inhibitors tested at $\mathrm{C}_{\text {trough }}$ concentrations were able to eliminate $\mathrm{DCV}+$ ASV-resistant replicons (Fig. 2b). Moreover, SOF as a single agent exhibited low clearance activity in this assay. Although the $\mathrm{C}_{\text {trough }}$ of $\operatorname{SOF}(1,100 \mathrm{nM})$ is higher than the $\mathrm{EC}_{50}(147 \mathrm{nM})$, it is below the estimated SOF $\mathrm{EC}_{90}(1,230 \mathrm{nM})$. Furthermore, the metabolism and efficiency of phosphorylation of SOF appear to be lower in hepatoma cell lines compared with primary hepatocytes. An analysis of the mechanism of activation of SOF and its analogs has demonstrated that some enzymes in these metabolic pathways, such as CES1, are expressed at significantly lower levels in Huh7 
A

GT 1b wild-type

Day 3

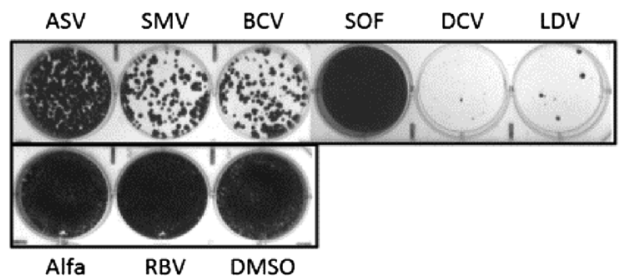

Day 7

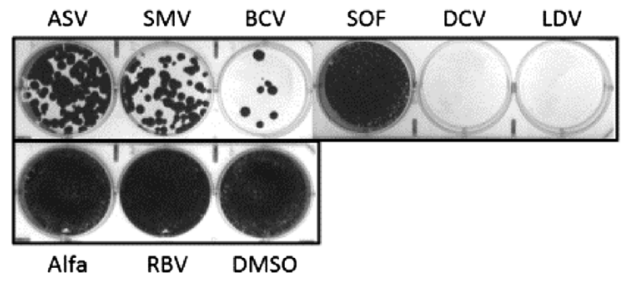

C

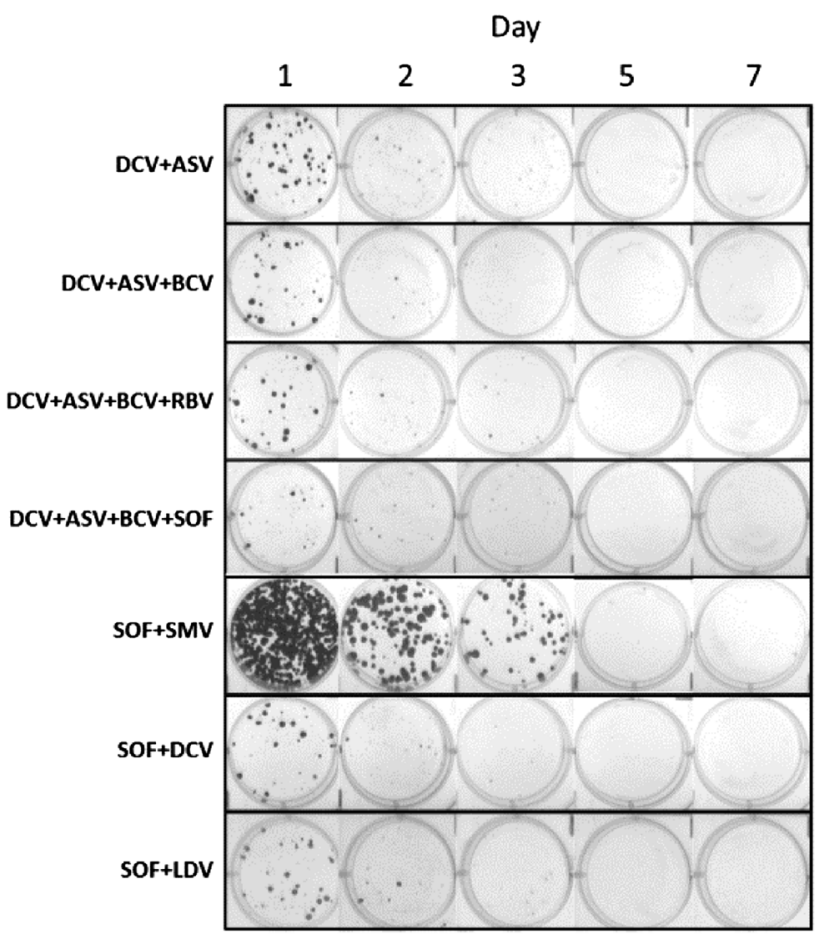

B GT 1b NS3-D168V

NS5A-L31M-Y93H
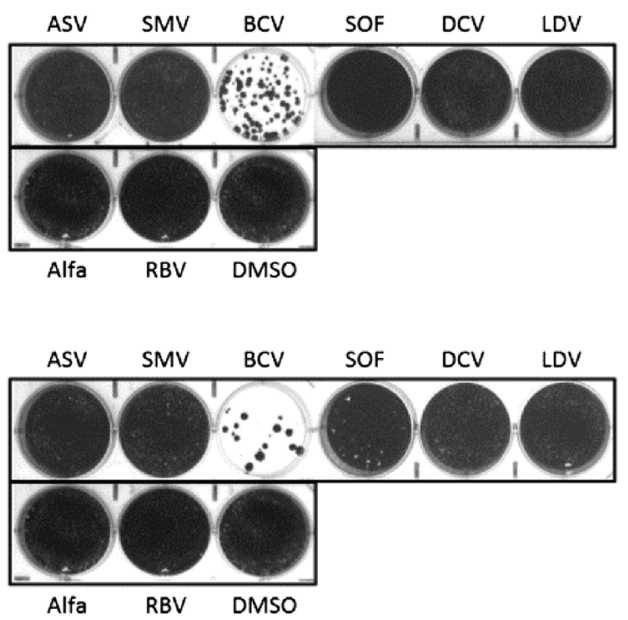

D GT 1b NS3-D168V NS5A-L31M-Y93H

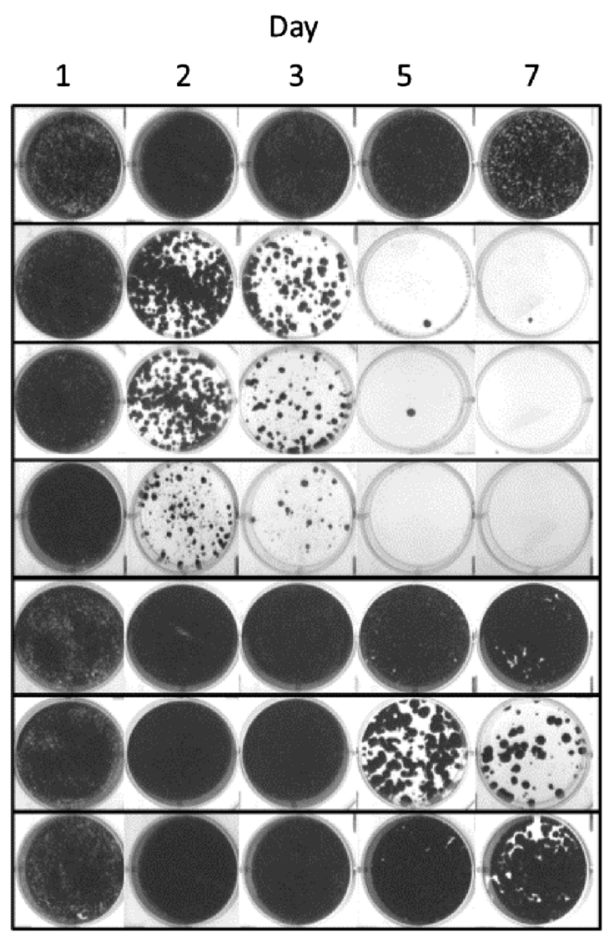

Fig. $2 \mathrm{HCV}$ replicon elimination assays with single agents and combination regimens using concentrations representing $\mathrm{C}_{\text {trough }}$ values observed in a clinical setting in wild-type GT-1b ( $\mathbf{a}$ and c) and DCV + ASV-resistant (NS3-D168V, NS5A-L31M$\mathrm{Y} 93 \mathrm{H})$ replicon cell lines $(\mathbf{b}$ and $\mathbf{d})$. Alfa peginterferon alfa,
$A S V$ asunaprevir, $B C V$ beclabuvir, $C_{\text {trough }}$ trough plasma concentrations, $D C V$ daclatasvir, $D M S O$, dimethyl sulfoxide, $G T$ genotype, $H C V$ hepatitis $\mathrm{C}$ virus, $L D V$ ledipasvir, NS3 non-structural protein 3, NSSA non-structural protein 5A, $R B V$ ribavirin, $S M V$ simeprevir, $S O F$ sofosbuvir 
cells compared with primary hepatocytes [11]; thus, the anti-HCV activity of SOF in repliconbased assays may not correlate with its activity in vivo. Similar instances of low activity with nucleosides in hepatoma-derived Huh7 cells harboring replicons have been reported $[12,13]$. However, SOF has a high barrier to resistance and has demonstrated efficacy in combination regimens. For wild-type replicons, all DAA combinations at $\mathrm{C}_{\text {trough }}$ concentrations that included an NS5A inhibitor eliminated replicons with high efficiency (Fig. 2c). In comparison, elimination of wild-type replicons was less efficient with SOF + SMV and peginterferon alfa-based combinations (Fig. 2c and Supplementary Fig. 2). Complete elimination of DCV + ASVresistant replicons occurred by day 7 with the three-DAA regimen $(\mathrm{DCV}+\mathrm{ASV}+\mathrm{BCV}) \pm \mathrm{RBV}$ or with the four-DAA regimen $(\mathrm{DCV}+\mathrm{ASV}+\mathrm{BCV}+\mathrm{SOF})$ (Fig. 2d). Replicon elimination profiles were comparable in wildtype and DCV + ASV-resistant cell lines following treatment with peginterferon alfa/ RBV-based regimens combined with SOF or $\mathrm{BCV}$, or the DAA-only combination of SOF with a next-generation NS3 protease inhibitor (Supplementary Fig. 2).

\section{DISCUSSION}

In summary, these in vitro experiments demonstrate that there are a number of potential alternate all-oral DAA treatment options available for genotype $1 b$-infected patients who experience virologic escape during DCV + ASV therapy. These include the three-DAA regimen of $\mathrm{DCV}+\mathrm{ASV}+\mathrm{BCV}$ combined with RBV or SOF, or other SOFbased combinations. Furthermore, the results suggest that a peginterferon alfa/RBV-based regimen with agents targeting NS5B could also provide effective therapy for these patients. Results from this in vitro study will require further evaluation in clinical studies. The efficacy of re-treating patients who have failed prior boceprevir or telaprevir therapy with multiple DAAs (DCV + SOF, SOF + LDV) has already been demonstrated, with sustained virologic response rates of up to $99 \%$ achieved with 24 weeks of treatment [14, 15]. However, studies on the treatment of patients with resistance to multiple DAAs are more limited; existing data suggest that effective options are available, and that it may also be possible to retreat patients with DAAs from the same drug class when combining with additional agents targeting complementary mechanisms of action [16-19].

\section{CONCLUSION}

Our in vitro results indicate that re-treatment with DAAs of the same class plus additional DAAs targeting different mechanisms of action resulted in clearance of replicons similar to wild-type replicons. This was observed when $\mathrm{DCV}+$ ASV-resistant replicons were treated with $\mathrm{DCV}+\mathrm{SOF}, \quad$ SOF + LDV and $\mathrm{DCV}+\mathrm{ASV}+\mathrm{BCV}+$ SOF. Re-treatment data in the clinic are currently minimal; however, patients have been successfully retreated with the same DAAs plus the addition of another agent.

\section{ACKNOWLEDGMENTS}

Sponsorship and article processing charges for this study were funded by Bristol-Myers Squibb, Wallingford, USA. Editorial assistance was provided by Andrew Street, ArticulateScience, Manchester, UK and was funded by Bristol- 
Myers Squibb, Wallingford, USA. All named authors meet the ICMJE criteria for authorship for this manuscript, take responsibility for the integrity of the work as a whole, and have given final approval to the version to be published.

Conflict of interest. Jacques Friborg is an employee of Bristol-Myers Squibb. Nannan Zhou is an employee of Bristol-Myers Squibb. Zhou Han is an employee of Bristol-Myers Squibb. Xiaoyan Yang is an employee of Bristol-Myers Squibb. Paul Falk is an employee of Bristol-Myers Squibb. Patricia Mendez is an employee of Bristol-Myers Squibb. Fiona McPhee is an employee of Bristol-Myers Squibb.

Compliance with ethics guidelines. This article does not contain any new studies with human or animal subjects performed by any of the authors.

Open Access. This article is distributed under the terms of the Creative Commons Attribution Noncommercial License which permits any noncommercial use, distribution, and reproduction in any medium, provided the original author(s) and the source are credited.

\section{REFERENCES}

1. Gao M, Nettles RE, Belema M, et al. Chemical genetics strategy identifies an HCV NS5A inhibitor with a potent clinical effect. Nature. 2010;465(7294):96-100.

2. McPhee F, Sheaffer AK, Friborg J, et al. Preclinical profile and characterization of the hepatitis $C$ virus NS3 protease inhibitor asunaprevir (BMS-650032). Antimicrob Agents Chemother. 2012;56(10):5387-96.

3. Manns M, Pol S, Jacobson IM, et al. All-oral daclatasvir plus asunaprevir for hepatitis $\mathrm{C}$ virus genotype $1 \mathrm{~b}$ : a multinational, phase 3 , multicohort study. Lancet. 2014;384(9941):414-29.
4. Kumada H, Suzuki Y, Ikeda K, et al. Daclatasvir plus asunaprevir for chronic HCV genotype $1 \mathrm{~b}$ infection. Hepatology. 2014;59(6):2083-91.

5. McPhee F, Friborg J, Levine S, et al. Resistance analysis of the hepatitis C virus NS3 protease inhibitor asunaprevir. Antimicrob Agents Chemother. 2012;56(7):3670-81.

6. Raboisson $\mathrm{P}$, de Kock $\mathrm{H}$, Rosenquist $\mathrm{A}$, et al. Structure-activity relationship study on a novel series of cyclopentane-containing macrocyclic inhibitors of the hepatitis C virus NS3/4A protease leading to the discovery of TMC435350. Bioorg Med Chem Lett. 2008;18(17):4853-8.

7. Sofia MJ, Bao D, Chang W, et al. Discovery of a betad-2'-deoxy-2'-alpha-fluoro-2'-beta-C-methyluridine nucleotide prodrug (PSI-7977) for the treatment of hepatitis C virus. J Med Chem. 2010;53(19): 7202-18.

8. Link JO, Taylor JG, Xu L, et al. Discovery of ledipasvir (GS-5885): a potent, once-daily oral NS5A inhibitor for the treatment of hepatitis C virus infection. J Med Chem. 2014;57(5):2033-46.

9. Friborg J, Levine S, Chen C, et al. Combinations of lambda interferon with direct-acting antiviral agents are highly efficient in suppressing hepatitis $\mathrm{C}$ virus replication. Antimicrob Agents Chemother. 2013;57(3):1312-22.

10. Wang C, Jia L, O'Boyle DR 2nd, et al. Comparison of daclatasvir resistance barriers on NS5A from hepatitis $C$ virus genotypes 1 to 6 : implications for cross-genotype activity. Antimicrob Agents Chemother. 2014;58(9):5155-63.

11. Murakami E, Tolstykh T, Bao H, et al. Mechanism of activation of PSI-7851 and its diastereoisomer PSI-7977. J Biol Chem. 2010;285(45):34337-47.

12. Berke JM, Vijgen L, Lachau-Durand $\mathrm{S}$, et al. Antiviral activity and mode of action of TMC647078, a novel nucleoside inhibitor of the hepatitis C virus NS5B polymerase. Antimicrob Agents Chemother. 2011;55(8):3812-20.

13. Ma H, Jiang WR, Robledo N, et al. Characterization of the metabolic activation of hepatitis $\mathrm{C}$ virus nucleoside inhibitor beta-D-2'-Deoxy-2'-fluoro- 2 'C-methylcytidine (PSI-6130) and identification of a novel active $5^{\prime}$-triphosphate species. J Biol Chem. 2007;282(41):29812-20.

14. Sulkowski MS, Gardiner DF, Rodriguez-Torres M, et al. Daclatasvir plus sofosbuvir for previously treated or untreated chronic HCV infection. N Engl J Med. 2014;370(3):211-21. 
15. Afdhal N, Reddy KR, Nelson DR, et al. Ledipasvir and sofosbuvir for previously treated HCV genotype 1 infection. N Engl J Med. 2014;370(16):1483-93.

16. Lawitz E, Poordad FF, Pang PS, et al. Sofosbuvir and ledipasvir fixed-dose combination with and without ribavirin in treatment-naive and previously treated patients with genotype 1 hepatitis $\mathrm{C}$ virus infection (LONESTAR): an openlabel, randomised, phase 2 trial. Lancet. 2014;383(9916):515-23.

17. Pol S, Sulkowski M, Hassanein T, et al. Successful retreatment with sofosbuvir of $\mathrm{HCV}$ genotype-1 infected patients who failed prior therapy with peginterferon + ribavirin plus 1 or 2 additional direct-acting antiviral agents. J Hepatol. 2014;60(1 Suppl):S23.

18. Osinusi A, Marti M, Townsend K, et al. Retreatment of relapsers to sofosbuvir/ribavirin with sofosbuvir/ ledipasvir: complete and rapid virologic suppression by week 4. J Hepatol. 2014;60(1 Suppl):S5-6.
19. Esteban R, Nyberg L, Lalezari J, et al. Successful retreatment with sofosbuvir-containing regimens for $\mathrm{HCV}$ genotype 2 or 3 infected patients who failed prior sofosbuvir plus ribavirin therapy. J Hepatol. 2014;60(1 Suppl):S4-5.

20. Lawitz EJ, Gruener D, Hill JM, et al. A phase 1, randomized, placebo-controlled, 3-day, doseranging study of GS-5885, an NS5A inhibitor, in patients with genotype 1 hepatitis C. J Hepatol. 2012;57(1):24-31.

21. Morello J, Soriano V, Barreiro P, et al. Plasma ribavirin trough concentrations at week 4 predict hepatitis $\mathrm{C}$ virus (HCV) relapse in HIV-HCVcoinfected patients treated for chronic hepatitis C. Antimicrob Agents Chemother. 2010;54(4):1647-9.

22. Bressler BL, Guindi M, Tomlinson G, Heathcote J. High body mass index is an independent risk factor for nonresponse to antiviral treatment in chronic hepatitis C. Hepatology. 2003;38(3):639-44. 